\title{
Evidence for the Transneuronal Regulation of Cerebellin Biosynthesis in Developing Purkinje Cells
}

\author{
J. Randall Slemmon, ${ }^{1 a}$ Dan Goldowitz, ${ }^{2}$ Russell Blacher, ${ }^{3}$ and James I. Morgan ${ }^{1}$ \\ 'Department of Neurosciences, Roche Institute of Molecular Biology, Roche Research Center, Nutley, New Jersey 07110 , \\ 'Department of Anatomy, Thomas Jefferson University, Philadelphia, Pennsylvania 19107, and "Applied Biosystems Inc., \\ Foster City, California 94404
}

We have investigated the expression of a unique class of neuropeptides, the cerebellins, in normal and neurodevelopmentally mutant mice. Employing HPLC separation, gasphase Edman sequencing, and immunocytochemistry, the normal Balb/c mouse cerebellum is shown to contain 2 Purkinje cell-specific neuropeptides, cerebellin and des-Ser'cerebellin. In this strain of mouse the cerebellins appear during early postnatal development and their subsequent levels parallel the most dramatic period of cerebellar development: granule cell migration and parallel fiber formation, synaptogenesis, Purkinje cell dendritic maturation, and establishment of adult cytoarchitecture. In mutant mice (reeler, weaver, and staggerer), in which these early developmental events are markedly disrupted, Purkinje cells contain much lower levels of cerebellin and des-Ser'-cerebellin. In general there is a correlation between the formation and number of parallel fiber-Purkinje cell synapses and cerebellin levels. For example, the staggerer mutant, which totally lacks these synapses, is essentially devoid of cerebellin, whereas in reeler, cerebellin seems to be dependent upon the position of individual Purkinje cells and their ability to form contacts with granule cells. These results indicate that granule cells can modulate the level of cerebellin in Purkinje cells. A number of models to explain these data are discussed.

A fundamental goal in the study of neurodevelopment has been to establish the nature of the regulatory mechanisms that underpin the orderly assembly of the nervous system. To extend our understanding of these control mechanisms to the molecular level we have attempted to identify developmentally regulated gene products of the cerebellum (Slemmon et al., 1984; Ziai et al., 1986), a neural structure whose maturation is modified by chemical and genetic means. We have previously determined that the rat brain contains 2 peptides, cerebellin and des-Ser'cerebellin, that are restricted to cerebellar Purkinje neurons (Slemmon et al., 1984, 1985) and neurons of the dorsal cochlear nucleus (Mugnaini and Morgan, 1987), which are thought to be homologs of Purkinje cells (Wouterlood and Mugnaini, 1984). The levels of these peptides are developmentally regulated in

Reccived Jan. 21, 1988; revised May 10, 1988; accepted May 10, 1988

Correspondence should be addressed to James I. Morgan, Ph.D., at the above address.

Present address: Department of Biochemistry, University of Rochester Medical Center, 601 Elmwood Avenue, Rochester, NY 14642.

Copyright $(\mathcal{C} 1988$ Society for Neuroscience $0270-6474 / 88 / 124603-09 \$ 02.00 / 0$ the cerebellum and anti-cerebellin antibodies have been used to follow Purkinje cell maturation (Slemmon et al., 1985). While the function of cerebellin is unknown, biochemical (Slemmon et al., 1984) and immunological (Mugnaini et al., 1988) evidence shows the peptides to be concentrated in the postsynaptic apparatus of Purkinje cells. Since the cercbellin sequence also has a significant homology to the polyimmunoglobulin receptor (Morgan et al., 1988; Mugnaini et al., 1988), it is supposed that the precursor for cerebellin might be involved in the recognition and transport of a ligand.

In the present study, cerebellin expression in neurological mutant mice that exhibit defined cellular aberrations of the cerebellum was examined to determine the proximate relationship between cerebellin levels and cerebellar ncurodevelopment. The mutants employed were weaver (Rakic and Sidman, 1973). reeler (Mariani et al., 1977), and staggerer (Sidman et al., 1962); these mutants display dramatic early postnatal effects on cerebellar Purkinje cells and nervous (Sidman and Green, 1970) and Purkinje cell degeneration (Mullen et al., 1976), which have a much later expression of the mutant phenotype in Purkinje cells. The level of the cerebellin peptides were quantitated by highperformance liquid chromatographic analysis in all the above mutants, while the cellular distribution of peptide immunoreactivity was analyzed with immunocytochemistry in the early phenotype mutants.

\section{Materials and Methods}

Mutant mice. Mutant mice and normal sex-matched, littermates were purchased from Jackson Laboratories (Bar Harbor, ME). Details of genetics are given in Table 1 . The mating schemes for reeler, staggerer, and weaver involved heterozygous crosses. This means that two-thirds of the normal littermates were heterozygotes and one-third were wildtype. Thercfore, it is conceivable that we may have underestimated the cerebellin content in wild-type because of the presence of heterozygotes.

Immunocytochemistry. Mice of the indicated strains were anesthetized and perfused via the ascending aorta with $4 \%$ buffered paraformaldchyde. Subsequent processing and sectioning of the brain tissues were as described previously (Slemmon et al., 1985). Peroxidase visualization was carried out using the Vectastain ABC Kit against rabbit lgG (Vector Laboratories, Burlingame, CA). Primary antibody and all other antibody reagents were diluted in $75 \mathrm{~mm}$ sodium phosphate, 75 mM sodium chloride containing $0.2 \%$ Nonidet P40 and applied for 2 $\mathrm{hr}$. Sections were washed for $30 \mathrm{~min}$ between antibody incubations in dilution buffer and peroxidase was visualized as described in the Vectastain $\mathrm{ABC}$ protocol. In all immunocytochemical studies reported here, adjacent sections were processed identically except that the anti-cerebellin antibody was preincubated with $10 \mathrm{nmol} / \mathrm{ml}$ of synthetic cerebellin. In all cases this completely blocked immunoreactivity.

Peptide isolation and quantitation by high-performance liquid chromatography (HPLC). Mice of the indicated strains and ages were decapitated and their cerebella rapidly removed and frozen in liquid ni- 


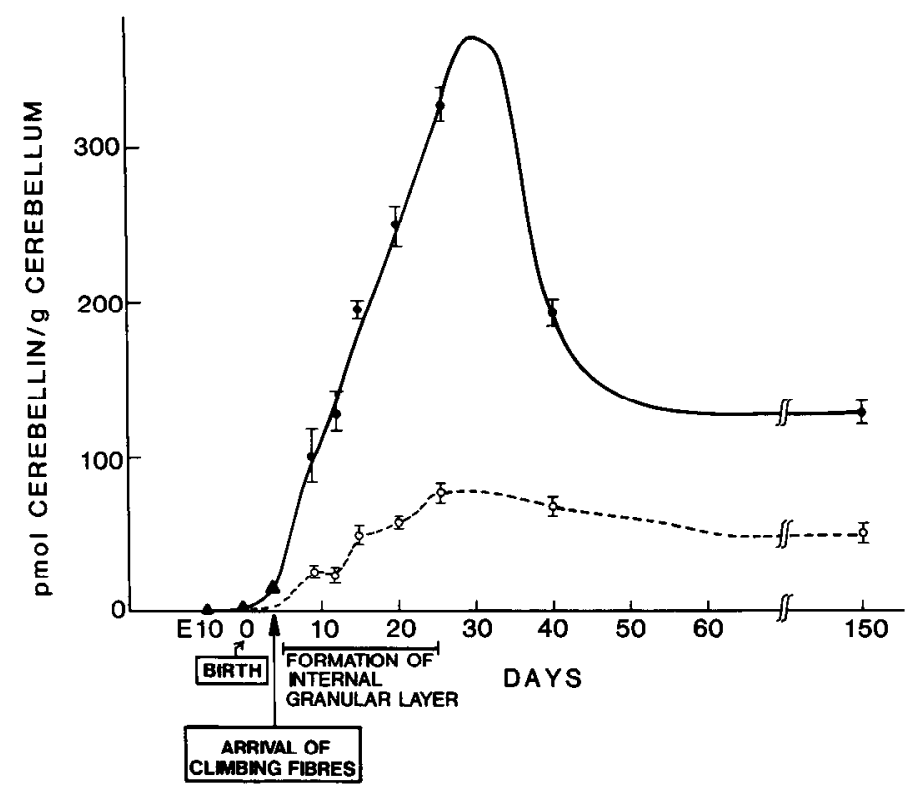

Figure 1. Developmental expression of the cerebellins in the mouse cerebellum. The cerebella from $15-20 \mathrm{Balb} / \mathrm{c}$ mice at each age indicated were used as starting material to isolate and quantitate the 2 peptides by ion-pairing IIPLC (Slemmon et al., 1984) (solid line, cerebellin; broken line, des-Ser ${ }^{1}$-cerebellin). Recovery of the peptides from all samples was evaluated using synthetic material and found to be in excess of $90 \%$ in all cases. Quantitation was determined by peak area against a calibration curve of synthetic cerebellin, data being the means \pm SEM of 4 determinations. Data points indicated by triangles were derived from HPLC-purified extracts using a specific cerebellin radioimmunoassay (Morgan et al., 1988). This was necessary since cerebellin levels in neonatal mice were below the detection limit of HPLC.

trogen to preclude peptide hydrolysis. Subsequently, the tissues were homogenized in guanidine hydrochloride and desalted on disposable C.18 cartridges (Sep Pak C18, Waters Associates, Milford, MA) as detailed previously (Slemmon et al., 1984). For quantitation, the desalted material was analyzed by ion-pairing HPLC using a postcolumn fluorescamine detector exactly as described for cerebellin (Slemmon et al., 1984, 1985). The chromatogram was calibrated using synthetic cerebellin. The recovery of endogenous cerebellin has been determined to be in excess of $90 \%$ using the same synthetic peptide added at the guanidine hydrochloride-homogenization step (data not shown).

In one experiment the peptide concentration was determined by a specific cerebellin radioimmunoassay (Morgan et al., 1988) following HPLC purification. This assay is approximately 10 times more sensitive than HPLC alone and was necessary to determine cerebellin levels in neonatal mouse brain.

Peptide sequencing. Guanidine hydrochloride extracts were made from the cerebella of $500 \mathrm{Balb} / \mathrm{c}$ mice (Charles River, 25-35 d old) and desalted as detailed previously (Slemmon et al., 1984). The crude desalted extract was first purified by semipreparative reverse-phase HPLC followed by a final separation into 2 homogeneous peaks by ion-pairing HPLC exactly as described for the rat cerebellins (Slemmon et al., 1984). This yielded $1.8 \mathrm{nmol}$ of cerebellin and $0.5 \mathrm{nmol}$ of des-Ser-cerebellin. Then, 200 pmol of each was hydrolyzed for amino acid analysis, while $500 \mathrm{pmol}$ and $300 \mathrm{pmol}$ of cerebellin and des-Ser-cerebellin, respectively, were used to determine sequence using an Applied BioSystems Inc. model $470 \mathrm{~A}$ gas-phase sequencer. The sequences are as follows: cerebellin, S-G-S-A-K-V-A-F-S-A-I-R-S-T-N-H; des-Ser ${ }^{1}$-cerebellin, G-S-A-K-V-A-F-S-A-I-R-S-T-N-H.

\section{Results}

In a preliminary study, it was determined that mouse cerebellum contained unique peaks on HPLC with the retention times of rat cerebellin and des-Ser'-cerebellin, respectivcly. Both peptides were isolated and sequenced and found to be identical to rat cerebellin and des-Ser ${ }^{1}$-cerebellin (see Materials and Methods).

During the normal development of the mouse cerebellum, the cerebellin peptides can be detected first by immunochemical analysis on about the third or fourth postnatal days (Fig. 1). Following their initial appearance the levels of both peptides rise rapidly to a maximum at approximately 25-30 d after birth, whereafter they fall to stable adult values. While this profile is qualitatively similar to that seen in the developing rat cerebellum, particularly with regards to the timing of the appearance and peak levels of expression of the cerebellins (Slemmon et al., 1985), quantitative differences are evident. The most notable difference is that des-Ser ${ }^{1}$-cerebellin is much less abundant than cerebellin in the mouse, whereas the former is the major cerebellin peptide in rat (Fig. 1) (Slemmon et al., 1985).

Immunocytochemical localization of the peptides showed them to be confined to the Purkinje cell soma and dendrites (Figs. 4, 5). Purkinje cell axons showed no peptide localization and the deep cerebellar nuclei were devoid of any terminal staining, indicating that cerebellins are selectively transported into the dendritic arbor. All Purkinje cells of the cerebellum were labclcd.

A clear pattern emerged on comparing the concentrations of the cerebellin peptides in normal and mutant mice. Mice bearing mutations that markedly affect early cerebellar development (reeler, weaver, and staggerer) showed dramatic declines in cerebellin content, whereas mutations that led to a much later death of Purkinje cells (nervous and Purkinje cell degeneration) showed only modest peptide reductions (Table 1). The observed reductions in the latter animals were consistent with the expected loss of Purkinje cells at the age $(n r, 35 \mathrm{~d} ; p c d, 27 \mathrm{~d})$ of the animals examined (Sidman and Green, 1970; Mullen et al., 1976; Mullen, 1977a). While the loss of peptide in Purkinje cell degeneration and nervous mice could be predicted, this is not the case for the loss of cerebellin in the other mutant mice, which have losses ranging between 25-90\% of the wild-type number of Purkinje cells (Herrup and Mullen, 1972, 1979, 1981; Blatt and Eisenman, 1985). It appeared from these results that the remaining Purkinje cells in the early cerebellar mutants had lost their ability to vigorously express the cerebellins.

The patten of loss in peptide expression in the early cerebellar mutants was investigated immunocytochemically using antibodies to the cerebellins. The reeler mouse (Fig. 2) exhibits the greatest perturbation in normal cerebellar architecture; as a result, Purkinje neurons can be seen throughout the cerebellar mass (Wilson et al., 1981). The Purkinje cells are primarily placed in 3 large masses (Goffinet et al., 1984) in the deep cerebellar area. These neurons have very low levels of cerebellinpositive immunoreactive staining. Cerebellin expression in the Purkinje cells located in the inner cerebellar mass appeared to be dependent on the proximity and number of adjacent granule cells. This can be seen in Figure $2 B$. The denser cluster of granule cells contains the most peptide-positive Purkinje cells, while regions devoid of granule cells have peptide-negative Purkinje cells. The greatest cerebellin expression was found in the few Purkinje cells that had successfully migrated to a position superficial to the granule cells with dendritic processes elaborated in the thin molecular layer (Fig. 2A). Thus, the expression of cerebellin in the reeler cerebellum seems to be related to a Purkinje cell's ability to interact with granule cells.

The weaver cerebellum (Fig. 3) can be scen to have retaincd more of its architectural organization than reeler and the Pur- 

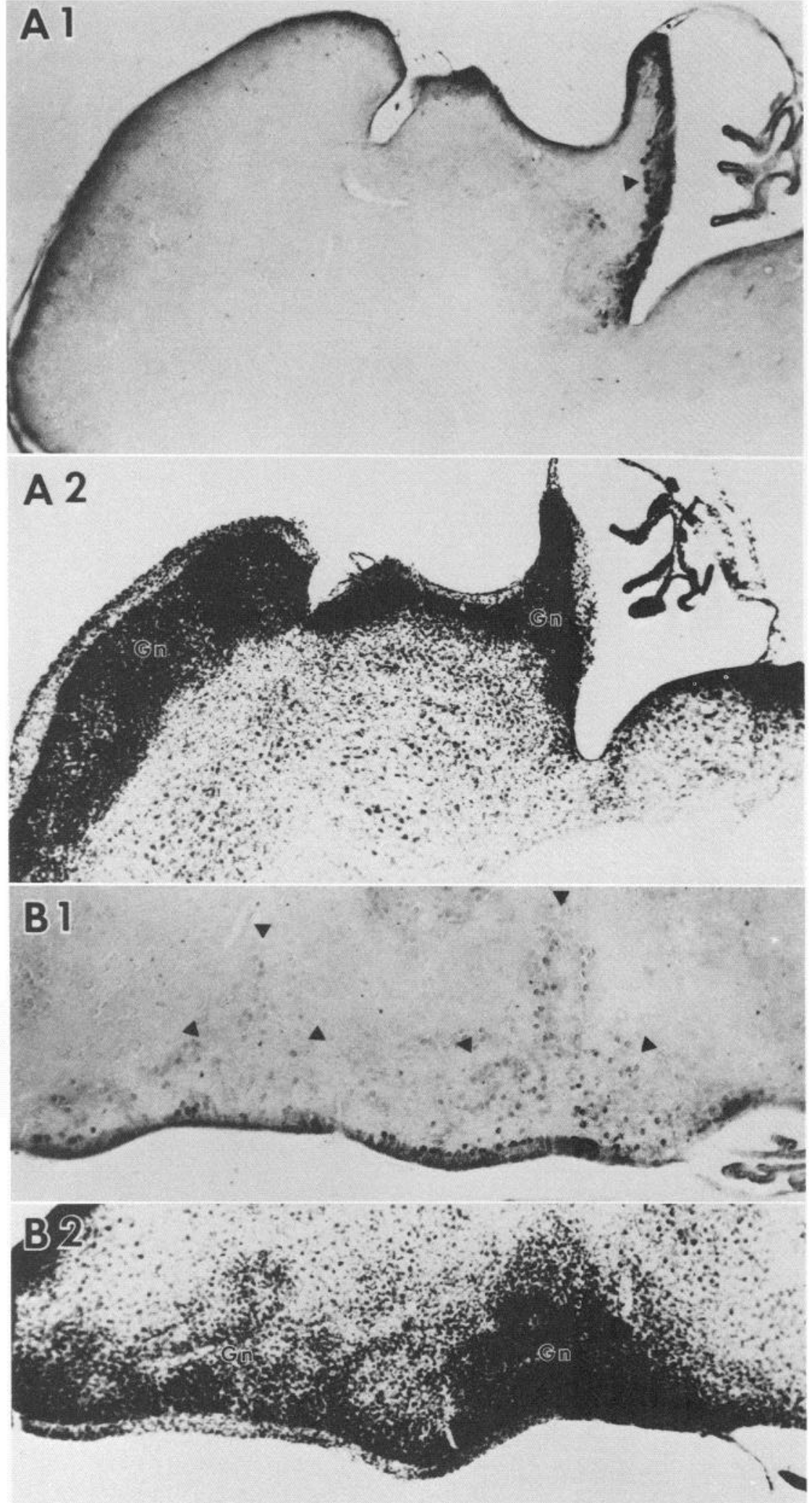

Figure 2. Immunocytochemical localization of the cerebellin peptides in the reeler mouse. $A 1$, Lateral view of a transverse section $(\times 100)$ processed for cerebellin localization. Solid arrowhead shows strongly positive set of Purkinje cells in the flocculonodular area. There are no positive cells in the interior cerebellar mass. A2, Nissl stain of an adjacent section confirming the presence of a small molecular layer and showing very few granule cells in the interior cerebellar mass. B1, Medial view of a transverse section processed for cerebellin localization. Purkinje cells that have migrated to the periphery show light cerebellin staining, except for the cells in the flocculonodular region, which stain more strongly. Ectopic Purkinje cells in the cerebellar mass show a quantitative appearance that depends on the density of the cluster of granule cells that they are located in (solid arrowheads). Ectopic Purkinje cells in regions devoid of granule cell neurons are peptide-negative. Lightly peptide-positive cells can be seen in the deep cerebellar nucleus. B2, Adjacent Nisslstained section shows dense granule cell populations in the region where ectopic Purkinje cells are peptide positive. The denser granule cell cluster contains more strongly peptide-positive Purkinje cell neurons. kinje cells are arranged in a loosely defined row just above the white matter of each folia (Rakic and Sidman, 1973). This animal is almost devoid of granule cells in the vermis and Purkinje cell somata in general showed no cerebellin-like immunoreactivity. Purkinje cell somata located in the flocculonodular region demonstrated the only clear cerebellin-positive staining (Fig. $3 B$ ). There was, however, cerebellin-like immunoreactivity in what appeared to be Purkinje cell processes in the molecular layer (Fig. 3A).

The absence of cerebellin-positive staining in Purkinje cells 
Figure 3. Immunocytochemical localization of cerebellin in weaver cerebellum. A, Sagittal section of a 30 d-old weaver cerebellum $(\times 100)$ processed for peptide visualization as described in Materials and Methods. $B$, Higher-power view $(\times 400)$ of the area indicated in $A$ showing poorly aligned Purkinje cells that are peptide positive (solid arrows). Purkinje cell bodies in all of the other lobes are cerebellin negative. $C$, Nissl substance stain of a section adjacent to that in $A$ showing an almost total loss of granule cell neurons and no internal granule cell layer $(\times 400)$. The corresponding area in $A$ is indicated. Solid arrows highlight the loose Purkinje cell plate which is occupied by a large number of these neurons.
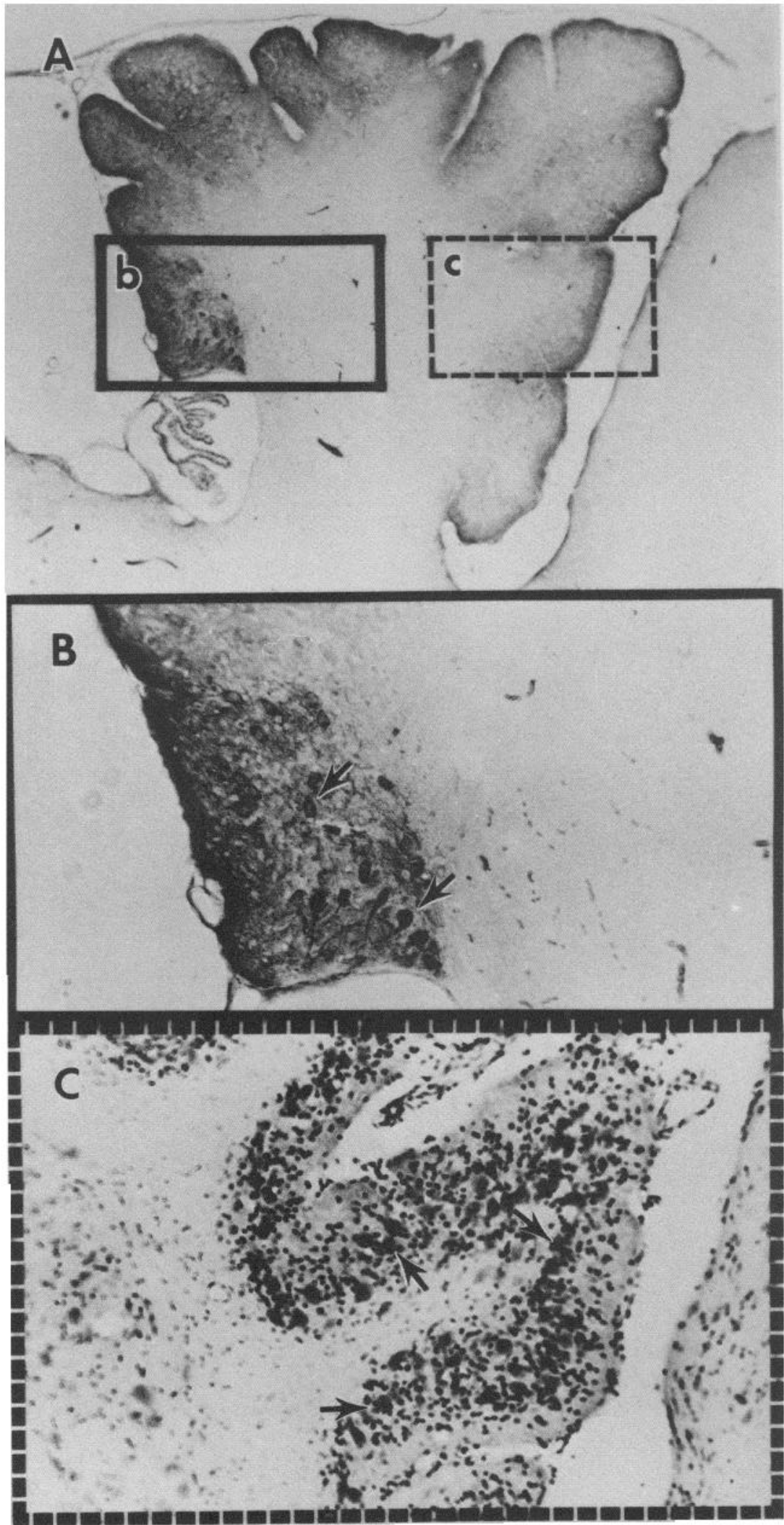

of the staggerer mouse was the most dramatic of the 3 early cerebellar mutants examined. There were no cerebellin-positive Purkinje cells visible in any region of this mutant's cerebellum. This included the area containing the flocculonodular lobe, which showed cerebellin-like immunoreactivity in both weaver and reeler. Figure 4 shows the cerebellin localization in a 15-d-old mutant and its control. There are no cerebellin-positive cells in this animal (Fig. $4 \mathrm{~A}$ ), even though there are granule cells present 

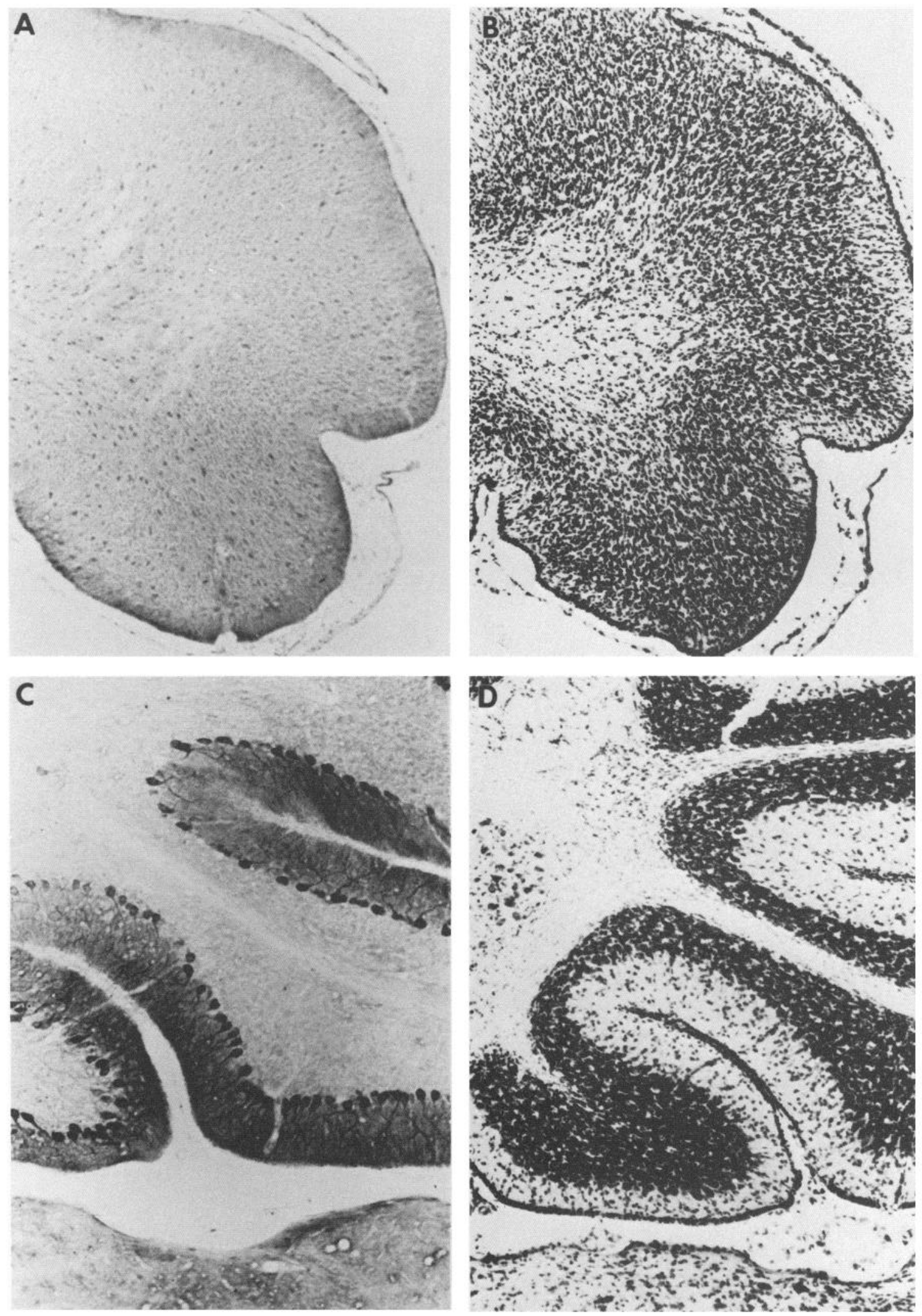

Figure 4. Immunocytochemical localization of cerebellin in a 15-d-old staggerer $(\times 100)$. A, Sagittal section from a staggerer. There are no cerebellinpositive Purkinje cells in any region of this animal's cerebellum. $B$, Cresyl violet staining of a section adjacent to that in $A$. There are still many granule cells present at this age, and the external granule cell layer can still be seen to contain premigratory granule cells. $C$, Cerebellin localization in a normal littermate. The pattern of peptide staining is essentially the same as originally observed in the rat, with strongly stained Purkinje cell soma and dendritic processes. $D$, Cresyl violet staining of a section adjacent to that in $C$. This section shows the normal architecture of the cerebellum, containing the well-defined molecular layer, Purkinje cell layer, and internal granule cell layer. 

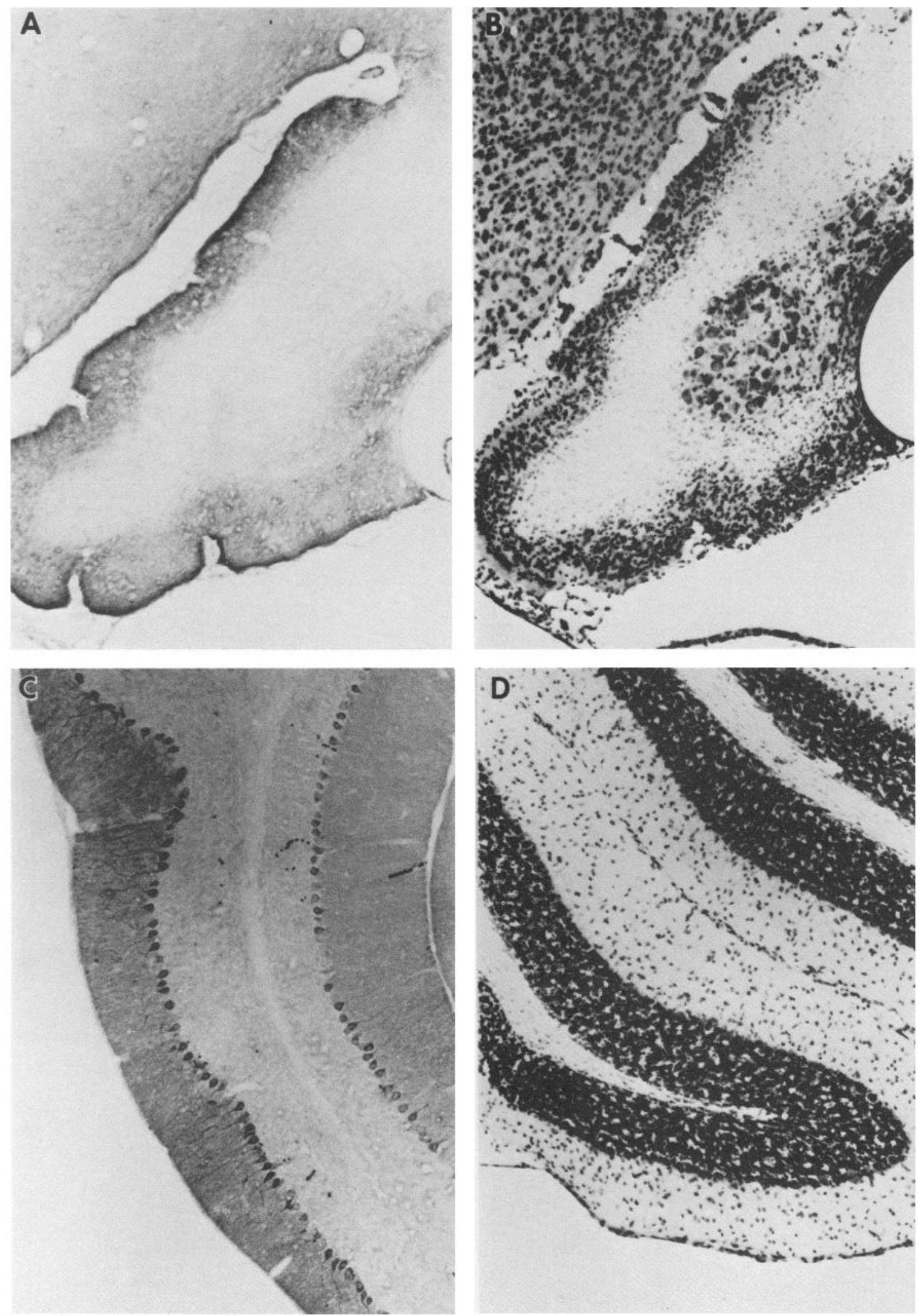

Figure 5. Cerebellin localization in a 30 -d-old staggerer mouse $(\times 100)$. A, Sagittal section from a staggerer mouse processed to show cerebellin localization. Like the 15-d-old mutant, there are no peptide-positive Purkinje cells in any region of this animal. $B$, Cresyl violet staining of a section adjacent to that in $A$. The granule cells have almost all disappeared by this age, but Purkinje cells persist. $C$, Littermate control for the 30 -d-old mutant. The Purkinje cells can be seen to be very peptide positive. $D$, Cresyl violet staining of a section adjacent to that in $C$. This animal shows the usual well-developed molecular, Purkinje cell, and internal granule cell layers. 
(Fig. $4 B$ ). In contrast, the littermate control shows very strong Purkinje cell staining (Fig. $4 C$ ). The 30 -d-old mutant in Figure 5 is also devoid of any cerebellin-positive Purkinje cells (Fig. $5 \mathrm{~A}$ ), while the littermate is normal (Fig. $5 \mathrm{C}$ ). This animal has lost most of its granule cells (Fig. $5 B$ ) and as a result the cerebellum is much reduced in size. It can also be seen that the cerebellar nuclear neurons evident in Figure $5 B$ are also unstained by the anti-cerebellin antibodies in an adjacent section (Fig. 5A).

\section{Discussion}

Cerebellin and des-Ser ${ }^{1}$-cerebellin were originally observed as cerebellum-specific peptides that were restricted to the cell soma and dendritic processes of Purkinje cell neurons (Fig. 1) (Slemmon ct al., 1985). The time course of their expression paralleled the postpartum development of this brain region in general and the migration of the external granule cells in particular. This association implicated the maturing granule cell neurons in the process of cerebellin expression. In order to examine this possibility more closely, cerebellin expression was analyzed in several mutant-mouse strains that possessed mutations affecting the development of the cerebellum.

The data from the mutant mice that have a later postnatal loss of Purkinje cells appears to be consistent with the known profile of neuron loss in pcd (mean age $27 \mathrm{~d}$; Caviness and Rakic, 1978; Landis and Mullen, 1978) and nervous (mean age $35 \mathrm{~d}$; Sidman and Green, 1970). Prior to the death of the Purkinje cells, cerebellin expression is near normal, showing that the cerebeilin gene is not the genetic locus involved in either mutant. The data from mutants that have a much earlier affect on cerebellar development, however, was much more striking. These mice showed a greater than $80 \%$ reduction in cerebellin expression compared with their littermates. The extent of cerebellin loss in all of these mutants is actually even more pronounced than is apparent from the data when presented on a weight basis since the cerebellum in the agranular mutants is small, resulting in an enrichment of Purkinje cells relative to tissue mass. This causes an elevation in cerebellin content when presented as pmol cerebellin/gm wet weight. As can be seen in Table 1, when cerebellin content is expressed on a per cerebellum basis, the agranular mutants show a $90 \%$ or greater reduction in peptide levels. In addition, both nervous and $p c d$ show a greater loss of cerebellin.

As part of all the mutants with early postnatal mutant phenotypes, the initial interactions between granule çells and Purkinje cells are severely disturbed. The nature of this disturbed relationship with respect to cerebellin expression was examined further by performing an immunocytochemical analysis on these mutants.

The weaver mutant has an almost complete loss of vermal granule cells. Consistent with the demonstrated loss of cerebellin peptide, almost all of the Purkinje cell bodies were negative for cerebellin-like immunoreactivity. The only exception was the presence of positive Purkinje cell somata in the flocculonodular region, which appeared to be able to express cerebellin in the absence of significant numbers of granule cells. In contrast to the Purkinje cell soma, staining was seen in dendrites in the shrunken molecular layer. Since the antiserum reacts not only with cerebellin but also larger, precursor, forms of the protein (Mugnaini et al., 1988), we presume this dendritic staining to represent antibody binding to unprocessed cerebellin-containing protein. The granule cells seem likely to be the cellular target
Table 1. Cerebellin levels in normal and cerebellar mutant mice

\begin{tabular}{|c|c|c|c|c|}
\hline \multirow[b]{2}{*}{ Mutation } & \multicolumn{2}{|l|}{ Mean } & \multicolumn{2}{|c|}{ Cerebellin content } \\
\hline & $\begin{array}{l}\text { age } \\
\text { (d) }\end{array}$ & Group & $\begin{array}{l}\mathrm{pmol} / \mathrm{gm} \\
\text { wet weight }\end{array}$ & $\begin{array}{l}\mathrm{pmol} / \mathrm{cere}- \\
\text { bellum }\end{array}$ \\
\hline Reeler & 20 & Control & 301 & 14.55 \\
\hline $\mathrm{B} 6 \mathrm{C} 3-\mathrm{a} / \mathrm{a}-\mathrm{rl}$ & & Mutant & $53(17.6 \%)$ & $0.88(6.1 \%)$ \\
\hline Weaver & 45 & Control & 209 & 9.95 \\
\hline B6CBA-A ${ }^{w-J} / A-w v$ & & Mutant & $34(16.3 \%)$ & $0.93(9.4 \%)$ \\
\hline Staggerer & 23 & Control & 240 & 11.40 \\
\hline B6C3-a/a-sg & & Mutant & $23(9.6 \%)$ & $0.65(5.7 \%)$ \\
\hline Purkinje cell & & & & \\
\hline degeneration & 27 & Control & 160 & 8.30 \\
\hline C57BL/6J-pcd & & Mutant & $119(74.4 \%)$ & $4.32(52 \%)$ \\
\hline Nervous & 35 & Control & 225 & 12.45 \\
\hline C3HeB/FeJ-nr & & Mutant & $120(53.3 \%)$ & $4.48(36 \%)$ \\
\hline
\end{tabular}

Cerebella from the indicated strains of mutant mice or their normal sex-matched littermates were removed and processed for the analysis of cerebellin as described in Materials and Methods. The results are given both as pmol cerebellin $/ \mathrm{gm}$ wet weight of cerebellum and as pmol/cerebellum (percentage of control cerebellin values are shown in parentheses). Also included is the mean age of the mice used. At least 17 cerebella were used per determination. All mice were obtained from Jackson Laboratory (Bar Harbor, ME).

of the wv gene (Goldowitz and Mullen, 1982; Goldowitz, 1986), and a primary disruption of Purkinje cell development and synaptogenesis is probably due to the lack of interactions with the granule cell parallel fibers. Since other synaptic interactions with Purkinje cells in $w v$ are preserved (or heightened) (Sotelo, 1975; Hirano et al., 1977), the data support the hypothesis that the presence of granule cells is required for normal cerebellin expression in all Purkinje cells except for those in the flocculonodular lobe.

The reeler mutant offered an opportunity to examine cerebellin expression in Purkinje cells that were located in several different cellular milieux. This was of special interest since the granule and Purkinje cells are not thought to be primary targets of the mutant gene, with the genetic defect more likely being localized to cells that are responsible for directing cell migration during development (Mariani et al., 1977; Mullen, 1977b). The pattern of cerebellin expression in this mutant depended on the general location of the Purkinje cell. Those Purkinje cells that successfully migrated towards the pial surface of the cerebellum, where they are associated with granule cells and positioned for parallel fiber innervation, demonstrated cerebellin-like immunoreactivity. Cerebellin expression in ectopic Purkinje cells located in the cerebellar mass also followed an apparent dependence on the number of surrounding granule cells. Purkinje cells located within clusters of granule cells were the most antibodypositive. This staining had a quantitative appearance, such that the denser the cluster of granule cells, the more strongly stained were the Purkinje cells. Ectopic Purkinje cells located in areas devoid of granule cells were peptide-negative. As in the weaver mutant, reeler Purkinje cells in cerebellar areas that would include the flocculonodular lobe were exceptions to this observation, since they could strongly express cerebellin even when there was a paucity of granule cells.

The staggerer mutant, which had the greatest loss of peptide, showed the most dramatic difference in cerebellin localization. There were no cerebellin-positive cells in any region of this cerebellum. This was true for mutant animals that were examined at days 15 (Fig. 4) and 30 (Fig. 5) postpartum, which 
either contained or were devoid of granule cells, respectively. The primary target of the staggerer mutation seems to be the Purkinje cell (Herrup and Mullen, 1979). However the mutation is manifested within the Purkinje cell a very obvious defect is an inability of granule cells to make contact with Purkinje cell spines. These spines are not only the sites of granule cell contact onto the Purkinje cells but also a major source of cerebellin peptide (Slemmon et al., 1984) and cerebellin-like immunoreactivity (Mugnaini et al., 1988). Apparently, cerebellin expression is grossly attenuated when they are obliterated. This would account for why the flocculonodular lobe in this mutant, unlike reeler and weaver, does not contain cerebellin-positive Purkinje cells. Furthermore, the mutant data, when taken together, suggest that cerebellin expression is specific to the initial granule cell-Purkinje cell contact since (1) Purkinje cells in earlyacting mutations make contact with other incoming fibers (e.g., the climbing fibers), and (2) the later-acting mutations, which primarily affect Purkinje cell survival, do not affect cerebellin expression until cells begin to die.

The above findings would suggest that the cerebellin expression in Purkinje cells of the flocculonodular region in the reeler and weaver mutants could be the consequence of neuronal interactions not present in the rest of the cerebellum. This could be the case since the flocculonodular lobe has been observed to contain a different population of afferent terminals. For instance, the nodulus contains an increased cholinergic (Kasa et al., 1982) and decreased noradrenergic innervation (Woodward et al., 1971). The flocculonodular lobe also receives discrete populations of mossy fibers, which can form synapses with Purkinje cell neurons in agranular cerebella (Sotelo, 1975). Additionally, this cerebellar region can participate as an apparently separate entity during motor learning in the vestibuloocular reflex (Lisberger, 1982), further demonstrating the autonomy of the flocculonodular lobe. Finally, Purkinje cells of this lobe appear to migrate along a different path to the majority of cerebellar Purkinje neurons (Altman and Bayer, 1985). Thus, the unexpected cerebellin expression in this region of the reeler and agranular weaver cerebellum may be brought about by alternative contacts.

The developmental profile of cerebellin is also consistent with the interpretation that synapse formation plays an important role in cerebellin expression. Cerebellin levels in both rat (Slemmon et al., 1985) and mouse (Fig. 1) increase in parallel with the establishment of both the internal granule cell layer and molecular layer (Altman, 1972a-c). During this period, granule cell contacts are being established on Purkinje cells. Cerebellin levels reach a peak in the fourth wcck postpartum, after which there is a decline that follows the redistribution of Purkinje cell tertiary dendrites and the loss of synaptic spines (Weiss and Pysh, 1978; Sadler and Berry, 1984). The increase and decrease in cerebellin levels, therefore, parallel the increase and decrease in the number of synapses present on the Purkinje cell. Additionally, the earlier data from developing rat (Slemmon et al., 1985) demonstrated how cerebellin immunostaining had a quantitative appearance that increased during the establishment of the molecular layer. From the present data, it would appear that these characteristics of cerebellin-like immunostaining come from a quantitative dependence of cerebellin levels on synapse numbers and formation. That is, when more synapses are present on the Purkinje cell more peptide is expressed. More specifically, this seems to involve the granule cell-Purkinje cell synapse. In the Purkinje cells of $w v, r l$, and $s g$ mice, with little or no cerebellin immunoreactivity, other afferent systems are intact. In $s g$, in which synaptogenesis between granule and Purkinje cells is most severely limited, there is the greatest deficit in cerebellin activity. In the $r l$ cerebellum, there is a clear position-dependent expression of cerebellin: Purkinje cells in position to receive parallel fiber contacts express correspondingly greater immunoreactive staining for cerebellin. While we have argued that the deficit in cerebellin is brought about by a loss of granule cells and their contacts onto Purkinje cells, we cannot formally exclude the possibility that the converse is true, that is, that a prior deficit in cerebellin results in a loss of granule cells. However, 3 independent granuloprival mutants, having the affected gene expressed in 3 distinct cell types, all show a loss of cerebellin. Therefore, the simplest interpretation of the data is that granule cell loss is the causative agent.

The relationship between cerebellin levels and granule cell synapses could be the result of several mechanisms. First, granule cells may elaborate a signal that controls the transcription of the cerebellin gene. Alternatively, the presence of the synapse may influence the proteolytic processing of the cerebellin precursor protein. Finally, since the synapse is the site of a concentration of cerebellin, the removal of this reservoir may simply reduce the amount of cerebellin that can be harbored within a single Purkinje neuron. As argued above, the absence of cerebellin peptide in weaver but the presence of immunostaining in dendrites can be explained by one or both of the latter possibilities.

On the basis of current information, the ability to maintain cerebellin synthesis is not necessarily uniquely confined to granule cells. For instance, the climbing fibers could play a role, since they contact Purkinje cells at the same time as cerebellin is first detected on postpartum day 4 (Fig. 1) (Crepel, 1971; Slemmon et al., 1984). It is also conceivable that other afferent processes stimulate cerebellin expression, either as a part of the normal development of the cerebellum or as aberrant contacts that arise in agranular cerebella. However, the information from the reeler, staggerer, and weaver mutants allows one to make a strong argument for the granule cell as the inductive force for cerebellin expression.

By identifying a unique marker of Purkinje cell maturation it has been possible to demonstrate a transneuronal control mechanism influencing the level of expression of the cerebellin peptide during development. It should now be possible to assess, through molecular genetic techniques, at which level this control is operating, i.e., on transcription or on posttranslational processes.

\section{References}

Altman, J. (1972a) Postnatal development of the cerebellar cortex in the rat. 1 . The external germinal layer and the transitional molecular layer. J. Comp. Neurol. 145: 353-398.

Altman, J. (1972b) Postnatal development of the cerebellar cortex in the rat. II. Phases in the maturation of Purkinje cells and of the molecular layer. J. Comp. Neurol. 145: 399-464.

Altman, J. (1972c) Postnatal development of the cerebellar cortex in the rat. III. Maturation of the components of the molecular layer. J. Comp. Neurol. 145: 465-514.

Altman, J., and S. A. Bayer (1985) Embryonic development of the rat cerebellum. III. Regional differences in the time of origin, migration and settling of Purkinje cells. J. Comp. Neurol. 231: 42-65.

Blatt, G. J., and L. M. Eisenman (1985) A qualitative and quantitative light microscopic study of the inferior olivary complex of normal, reeler and weaver mutant mice. J. Comp. Neurol. 232: 117-128.

Caviness, V. S., and P. Rakic (1978) Mechanisms of cortical devel- 
opment: A view from mutations in mice. Annu. Rev. Neurosci. 1: 297-326.

Crepel, F. (1971) Maturation of climbing fibre responses in the rat. Brain Res. 35: 272-276.

Goffinet, A. M., K.-F. So, M. Yamamoto, M. Edwards, and V. S. Caviness (1984) Architectonic and hodological organization of the cerebellum in reeler mutant mice. Dev. Brain Res. 16: 263-276.

Goldowitz, D. (1986) Inter-specific mouse chimeras to study weaver mutant gene action and cell lineage in the CNS. Soc. Neurosci. Abstr. 12: 1583 .

Goldowitz, D., and R. J. Mullen (1982) Granule cell as a site of gene action in the weaver mouse cerebellum: Evidence from heterozygous mutant chimeras. J. Neurosci. 2; 1474-1485.

Herrup, K., and R. J. Mullen (1972) Regional variation and absence of large neurons in the cerebellum of the staggerer mouse. Brain Res. 172: $1-12$

Herrup, K., and R. J. Mullen (1979) Staggerer chimeras: Intrinsic nature of Purkinje defects and implications for normal cerebellar development. Brain Res. 178: 443-457.

Herrup, K., and R. J. Mullen (1981) Role of the staggerer gene in determining Purkinje cell number in the cerebellar cortex of mouse chimeras. Dev. Brain Res. 1: 475-485.

Hirano, A., H. M. Dembitzer, and C. H. Yoon (1977) Development of Purkinje cell somatic spines in weaver mouse. Acta Neuropathol. (Berl.) 40: 85-90.

Kasa, P., K. Bansaghy, Z. Radonczay, and K. Gulya (1982) Postnatal development of the acetylcholine system in different parts of the rat cerebellum. J. Neurochem. 39: 1726-1732.

Landis, S. C., and R. J. Mullen (1978) The development and degeneration of Purkinje cells in pcd mutant mice. J. Comp. Neurol. 177: 125-143.

Lisberger, S. G. (1982) Role of the cerebellum during motor learning in the vestibulo-ocular reflex. Different mechanisms in different species? Trends Neurosci. 5: 437-441.

Mariani, J., F. Crepel, K. Mikoshiba, J. P. Changeux, and C. Sotelo (1977) Anatomical, physiological and biochemical studies of the cerebellum from reeler mutant mouse. Philos. Trans. R. Soc. London 281: $1-28$.

Morgan, J. I., J. R. Slemmon, W. Danho, J. L. Hempstead, A. S. Berrebi, and E. Mugnaini (1988) Cerebellin and related postsynaptic peptides in the brain of normal and neurodevelopmentally mutant vertebrates. Synapse 2: 117-124.

Mugnaini, E., and J. I. Morgan (1987) The neuropeptide cerebellin is a marker for two similar neuronal circuits in rat brain. Proc. Natl. Acad. Sci. USA 84: 8692-8696.

Mugnaini, E., A.-L. Dahl, and J. I. Morgan (1988) Cerebellin is a postsynaptic neuropeptide. Synapse 2: 125-138.

Mullen, R. J. (1977a) Site of pcd action and Purkinje cell mosaicism in cerebella of chimeric mice. Nature 272: 245-247.
Mullen, R. J. (1977b) Genetic dissection of the CNS with mutantnormal mouse and rat chimeras. In Society for Neuroscience Symposia, W. M. Cowan and J. A. Ferrendelli, eds., Vol. 2, pp. 47-65, Society for Neuroscience, Bethesda, MD.

Mullen, R. J., E. M. Eicher, and R. L. Sidman (1976) Purkinje cell degeneration, a new neurological mutation in the mouse. Proc. Natl. Acad. Sci. USA 73: 208-212.

Rakic, P., and R. L. Sidman (1973) Sequence of developmental abnormalities leading to granule cell deficit in cerebellar cortex of weaver mutant mice. J. Comp. Neurol. 152: 103-132.

Sadler, M., and M. Berry (1984) Remodeling during development of the Purkinje cell dendritic tree in the mouse. Proc. R. Soc. London [Biol.] 221: 349-368.

Sidman, R. L., and M. C. Green (1970) "Nervous" a mutant mouse with cerebellar disease. In Les Mutants Pathologiques Chez l'Animal, M. Sabourdy, ed., pp. 69-79, Edition du Centre National de la Recherche Scientifique, Orleans-la-Source, France.

Sidman, R. L., P. W. Lane, and M. M. Dickie (1962) Staggerer, a new mutation in the mouse cerebellum. Science 137: 610-612.

Slemmon, J. R., R. Blacher, W. Danho, J. L. Hempstead, and J. I. Morgan (1984) Isolation and sequencing of two novel cerebellumspecific peptides. Proc. Natl. Acad. Sci. USA 81: 6866-6870.

Slemmon, J. R., W. Danho, J. L. Hempstead, and J. I. Morgan (1985) Cerebellin, a quantifiable marker for Purkinje cell maturation. Proc. Natl. Acad. Sci. USA 82: 7145-7148.

Sotelo, C. (1975) Anatomical, physiological and biochemical studies of the cerebellum from mutant mice. II. Morphological study of cerebellar cortical neurons and circuits in the weaver mouse. Brain Res. 94: $19-44$.

Weiss, G., and J. J. Pysh (1978) Evidence for loss of Purkinje cell dendrites during the late development: A morphometric Golgi analysis in the mouse. Brain Res. I54: 219-230.

Wilson, L., C. Sotelo, and V. S. Caviness (1981) Heterologous synapses upon Purkinje cells in the cerebellum of the reeler mutant mouse: An experimental light and electron microscopic study. Brain Res. 213: $63-82$.

Woodward, D. J., B. Hoffer, G. R. Siggins, and F. E. Bloom (1971) The ontogenetic development of synaptic junctions, synaptic activation and responsiveness to neurotransmitter substances in rat cerebellar Purkinje cells. Brain Res. 34: 73-97.

Wouterlood, F. G., and E. Mugnaini (1984) Cartwheel neurons of the dorsal cochlear nucleus. A Golgi-electron microscopic study in the rat. J. Comp. Neurol. 227: 136-157.

Ziai, M. R., Y.-C. E. Pan, J. D. Hulmes, L. Sangameswaran, and J. I. Morgan (1986) Isolation, sequence, and developmental profile of a brain-specific polypeptide, PEP-19. Proc. Natl. Acad. Sci. USA 83: 8420-8423. 